\title{
AC 2011-886: LEARNING TO LIVE WITH FLOODS: PEDAGOGICAL ADVANTAGES OF A THEMATIC SHORT COURSE CENTERED ON IN- TERNATIONAL EXPOSURE
}

Samuel James Boland, IIHR - Hydroscience and Engineering, The University of Iowa

Michael V. Schaefer, IIHR-Hydroscience and Engineering

Carmen M Langel

Taryn Michelle Tigges, The University of Iowa

Fabienne Bertrand, IIHR-Hydroscience and Engineering

Fabienne Bertrand is a recent Master's graduate in Civil and Environmental Engineering from the University of Iowa. She obtained the Fulbright Scholarship for Foreign Students in 2008 and attended a study abroad course in The Netherlands and the United Kingdom in 2010. Her interests include stream bank restoration, water quality and sediment transport modeling.

\section{Marian Muste, IIHR-Hydroscience \& Engineering, The University of Iowa}

Dr. Muste is Research Engineer at IIHR-Hydroscience \& Engineering, The University of Iowa (UI). He is Adjunct Professor with the Civil \& Environmental Engineering Department and has a complementary appointment with the UI's International Program. He holds graduate degrees in civil and environmental engineering with emphasis on experimental fluid mechanics and environmental hydraulics. His most recent area of research is the development of large-scale data/information management systems, sensors and senor networks, and their implementation in research and education focused on sustainable use of water and land resources. Dr Muste is author or co-author of more than 150 technical papers and 75 reports. Dr Muste is an active international research and educator. He is expert for UNESCO's International Hydrologic Program and World Meteorological Organization projects. He has extensive international experience a three-time Fulbright Fellow (2004, 2006, and 2009) and grantee of the Japan Society for the Promotion of Science. He is instructor of a unique course in the US International Perspectives in Water Science Resources and Management. He is member of the Council of the International Association of Hydro-Environment Engineering and Research.

\section{Mr. Zachary David Hingst}

BA in Global Studies, University of Iowa, 2005 MS in Urban \& Regional Planning, University of Iowa, 2010

(c)American Society for Engineering Education, 2011 


\title{
Learning to Live with Floods: Pedagogical Advantages of a Thematic Short Course Centered on International Exposure
}

\begin{abstract}
The increasingly global nature of all fields of engineering has created new pressures on educators to provide valuable international experience to their respective engineering students. The rigors of the highly demanding engineering curriculum that prevent enrollment in study abroad programs have been circumvented by the application of a short-term model that provides distinct logistical and pedagogical advantages over semester-long study abroad courses. The International Perspectives in Water Resource Science \& Management (IPWRSM) course is steeped in over ten years of history in international experiences that have been provided to both graduate students and undergraduate students alike. Recognizing the need to expose students to the international facets of the engineering and research workplaces, the IPWRSM course aims to provide students with the international experience gained in a traditional study abroad course while overcoming the obstacles to enrollment that result in typical under-representation of engineering students. In addition to providing engineering curriculum, an opportunity to connect engineering education organizations in different parts of the world is also made available.
\end{abstract}

A 2010 two week course to the Netherlands and the United Kingdom presents a case study that showcases the introduction to concepts present in differing academic and professional cultures. The theme of "Learning to Live with Floods" provided students experience to cutting-edge flood management and modeling techniques. This exposure enhanced students' academic goals in a fashion that would be impossible during the course of typical engineering curricula. The wide variety of lectures, presentations, and field trips are provided in a context that serves to acclimate students to a career that is increasingly likely to be multicultural and global. Surveys that were completed before and after the Netherlands/UK offering of the course, in conjunction with surveys from a previous IPWRSM course to Egypt, provide quantitative evidence towards the benefits of the short-term model. Evidence points toward the fact that the short-term study abroad model prepares students for the increasingly global environment of the engineering workplace, and the model must be developed further. This paper presents a discussion of the relevancy and success of the IPWRSM course and recommends that similar models be adopted if education institutions wish to prepare engineering students for a global workplace.

Need and Relevance of Studying Abroad in Engineering Curriculum

Globalization and internationalization have become commonplace terms across all sectors of the economy; the engineering field is no exception. While these words embody a broad variety of issues and opportunities, a major concern is that along with these terms come new obstacles that must be met with appropriate education and experience. This need has been identified by major 
institutions and deemed a high priority in research and education ${ }^{20,22}$. The Accreditation Board for Engineering and Technology (ABET) has mandated that one of the expected outcomes of a degree in engineering is that "graduates understand the impact of engineering in a global and societal context"7. Study abroad programs have been proposed as a source for this new demand, but a band-aid approach will not be sufficient for fitting the unique requirements of engineering curricula; study abroad programs must be adjusted to accommodate the typically highly regimented schedules of engineers' academic careers. Short-term study abroad programs have been shown to be appropriate and will likely become the new standard in preparing students for the global challenges that await them ${ }^{2}$.

With the identified need for globally competent engineers has come avid discussion on what is the best method for introducing students to this context and providing them with experience that can aid their careers. Most current efforts to prepare a globally competent workforce have been directed toward undergraduate education through international study abroad programs offered by several American universities ${ }^{10}$ and NSF-sponsored international Research Experiences for Undergraduates $^{19}$. Experiential learning theory proposes that lived experience is the most effective and enduring route for memory and learning ${ }^{11}$. Studying abroad is one of the few options that can provide experiential learning in an international setting, and has thus become a center-point in discussions $9,15,18$. Despite this fact and the knowledge that engineering is international, the participation of engineering students in study abroad programs is dismally low; roughly less than 3 percent $^{14}$. While there has been a recent rise in the popularity of study abroad programs in general, engineering students have not participated in this trend and are severely under-represented $^{5,10,12}$. This low turnout must be addressed, as it has been shown that study abroad experiences leave a lasting impact on participants that influence their personal and professional life for years to come $\mathrm{c}^{3}$.

There are a variety of reasons that prevent typical engineering students from participating in study abroad programs. Incorporating international experience into the typically highly regimented engineering curricula has proven to be a challenge that cannot always be met by study abroad programs ${ }^{13}$. Archetypal programs span a semester or year period, which almost never meshes well with a curriculum that squeezes as many major relevant courses into four years as possible. It is a common fear that studying abroad will lengthen the time required to graduate. Affordability, diversity of program, capacity, and transfer of credits are acknowledged to be key issues when students are deciding to take a study abroad course ${ }^{14,22}$. To address the limitations of conventional study abroad programs, short-term courses have been put forth as an option that can fit within a rigorous course load ${ }^{2}$.

Short-term international courses provide many opportunities that traditional study abroad courses cannot. One such opportunity is that courses can cater to focus areas of students while ensuring that proper credit will be received for participation. This implies that the international 
experience gained will be directly relevant to the students' interests and most likely their career path. Due to the short nature of the course, associated costs are likely to be less than semester or year-long study abroad programs. The International Perspectives in Water Resources Science and Management (IPWRSM) course is one such program that provides an international experience that is relevant to participants' field of study while having a duration that is approachable and will not impair graduation timelines.

The IPWRSM course provides this relevant experience while taking advantage of best practices that help to ensure the success of the course. Since the course is departmental, it takes advantage of the expedited process for incorporating international topics into an institutions curriculum and benefits gained through linkages between host and home curricula ${ }^{23}$. Additional features of the course that have been identified to increase the success of a program include involving several faculty members in a program, preparing students before departure, taking advantage of already existing university infrastructure, and a college leadership that has made a long term

commitment to the program $^{22}$. The course provides the now necessary international experience and exposure to multiculturalism while overcoming the barriers of traditional study abroad programs. The predominant goal of the IPWRSM course is to provide students with a unique experience that will aid in preparing them for the global engineering workplace.

International Perspectives Short-Course Background

The University of Iowa course was created in 1997 as an initiative of IIHR. It was developed in response to: 1) the increasing need for engineers and scientists to have a global perspective of water resources challenges; 2 ) the need for engineers and scientists from across the world to work together to develop solutions to our global water resources challenges; and 3) the lack of short-term, affordable international experiences available to engineering students. Since its inception, IPWRSM has taken 124 students on nine different international experiences (India, 1998; Taiwan \& Japan, 1999; China, 2000; Eastern Europe, 2001; Argentina \& Brazil, 2003; Turkey, 2005; China, 2007; and Egypt, 2008-2009; UK and Netherlands 2010) ${ }^{5}$ to introduce them to the realities and complexities of global water and environmental issues. A summary of the previous destinations is provided in Figure 1. The course seeks to provide in-depth exposure to technical, cultural, social, economic, environmental, and ethical issues and the associated interlinking complexities that influence major water resource projects in countries outside of the U.S. ${ }^{8}$. The course participants, structure, and unique itinerary make IPWRSM a stand-alone class that goes beyond the technical aspects of engineering, putting water resources engineering within the context of a different culture ${ }^{24}$.

Most IPWRSM registrants are graduate students in The University of Iowa's College of Engineering; however, students from other disciplines (generally liberal arts programs), engineering upperclassmen, and young engineering professionals also take IPWRSM. In 
addition, students from eight other domestic universities and colleges and from three international universities have participated in IPWRSM ${ }^{2}$. Thus, IPWRSM has become a truly international and multidisciplinary course, exposing students to new cultures while they interact with a diverse student and faculty group. Of note here is the fact that IPWRSM has been continuously subsidized by IIHR and the UI's Office of Study Abroad to help make it available to a wide student body ${ }^{24}$.

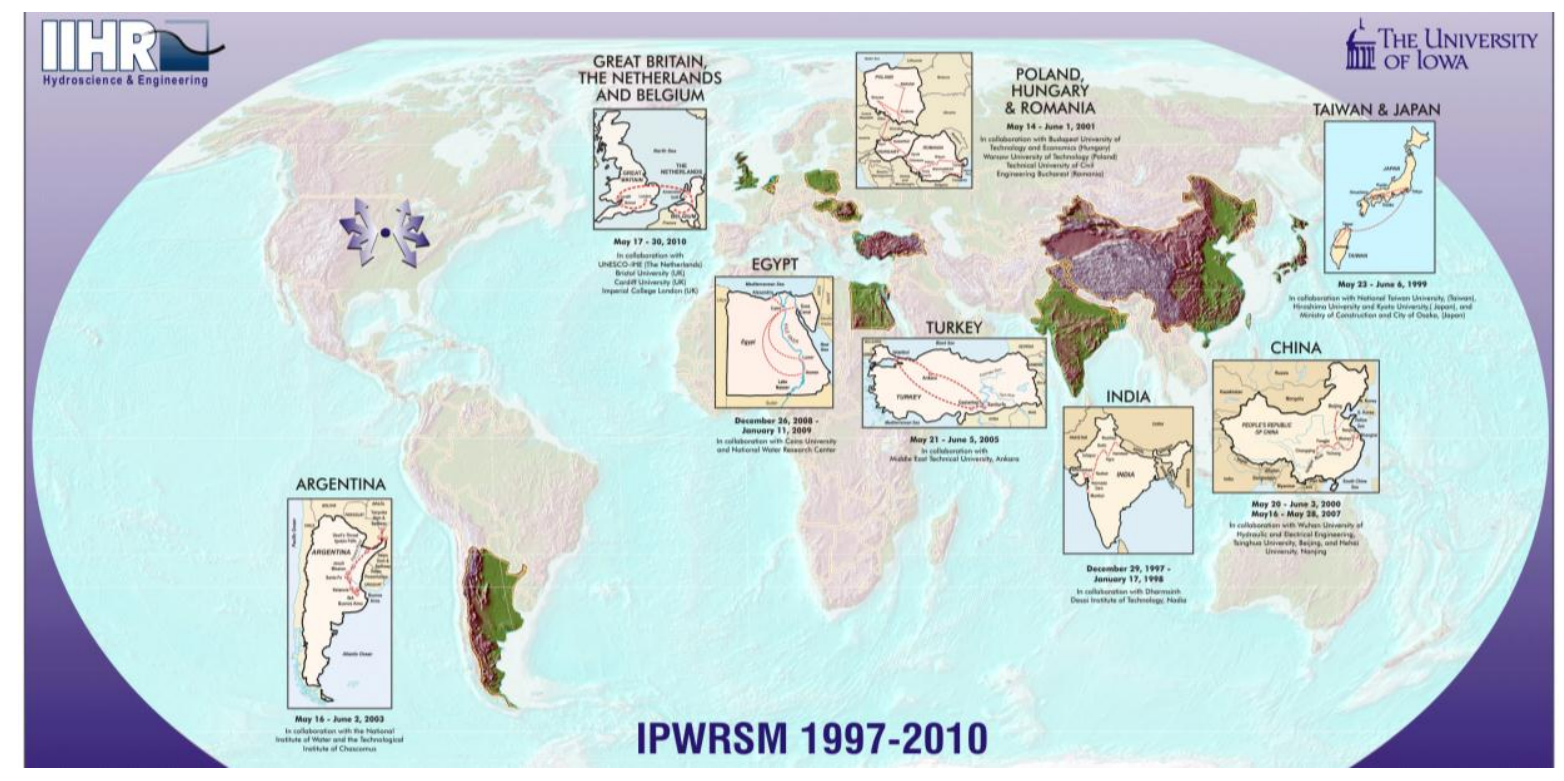

Figure 1: Previous offerings of the IPWRSM course.

The course structure makes each offering unique. Prior to the international experience, students attend a series of seminars and presentations covering the region's culture, history, politics, and other factors relevant to the region. These presentations, which may include speakers from the host country, offer important background and context for the international component. The international experience includes several specific components during an intense two to three week tour of the host country or region to better understand the complexity of issues that impact planning and execution of water projects in the region. First are visits to a variety of different water resources structures and laboratories. Advance arrangements are made for behind-thescenes tours of these facilities and to interact with local engineers for discussion of their unique challenges. Second, each tour includes an opportunity for students to meet and interact with engineering students and faculty at one or more universities. This includes formal time together (which includes a presentation about IIHR by course participants) and unstructured time interacting with each other ${ }^{24}$. The previous course offerings showed that the field trips and associated activities require a well structured management plan initiated at least one year from the date of the field trip. The yearly cycle of tasks associated with the course offering is listed in Table 1. 
Table 1: Annual tasks for course administration

\begin{tabular}{|l|l|l|l|}
\hline & \multicolumn{1}{|c|}{ Task } & \multicolumn{1}{|c|}{ Responsibility } & Sample Timeline \\
\hline 1 & Establish theme and country for course offering & PD $^{1}$, IP/OFSA & September \\
\hline 2 & Establish management team and identify host partners & PD, Co-D ${ }^{2}, \mathrm{H}^{3}$ & September \\
\hline 3 & Draft course objectives, budget and assess risks & PD, H, IP/OFSA & October \\
\hline 4 & Finalize course administration and website & PD, Co-D, H, IIHR & November \\
\hline 5 & Advertise the course and distribute applications & PD, IIHR & December \\
\hline 6 & Prepare the lecture series at home and host country & PD, H, IIHR, IP/OFSA & January \\
\hline 7 & Review candidates applications & PD, Co-D & February \\
\hline 8 & Finalize logistical arrangements and execute a planning visit & PD, Co-D, H & February \\
\hline 9 & Select participants and initiate visa and travel arrangements & PD, Co-D, IIHR & February \\
\hline 10 & $\begin{array}{l}\text { Initiate the home-lecture series, fine tune budget, disseminate } \\
\text { safety and security plan, develop contingency plan }\end{array}$ & PD, H, IIHR, IP/OFSA & $\begin{array}{l}\text { February- March- } \\
\text { April }\end{array}$ \\
\hline 11 & Start field trip, conduct on-site orientation & PD, Co-D, H & May \\
\hline 12 & Oversee on-site activities & PD, Co-D, H & May \\
\hline 13 & $\begin{array}{l}\text { Review individual research progress and organize departure } \\
\text { (surveys, closing event, discuss cultural shock }\end{array}$ & PD, E & May \\
\hline 14 & Return home, complete website, initiate written reports & PD, IIHR & May \\
\hline 15 & Close financial aspects and reports to designated offices & PD, IIHR, IP/OFSA & June \\
\hline 16 & Conduct course evaluation & PD, E & July \\
\hline 17 & Grade final reports, issue course certificates, finalize website & PD & August \\
\hline 18 & Summarize and report overall course experience & PD & September \\
\hline
\end{tabular}

Abroad Offices

Each IPWRSM participant is also required to complete an individual or group project. These projects vary depending on student interests, but generally include: research papers focusing on relevant water resources issues of concern to the world region of the course, incorporation of topics covered during the course into a student's research, development of a post-trip web site, and presentation materials to deliver in the host country ${ }^{24}$.

\section{A Unique Classroom through the Netherlands and the United Kingdom}

A diagram of the most recent course offering is presented below in Figure 2 to illustrate how a combination of professional and academic interactions, in addition to multiple excursions to engineering works, has been produced to provide students a unique educational experience. The course was structured in such a way that every experience related to the course theme of "Learning to Live with Floods," from academic research supporting immediate societal needs to gaining connections with host institutions. Different engineering methodologies from each respective region were also introduced to illustrate the variety of ways that societies have learned to live with floods. This course is the only option for University of Iowa students to gain this type of cultural exposure and provide such relevant context to engineering practices.

In order to prepare students for such a range of experiences, several pre-trip meetings occur during the months leading up to the departure date. These meetings help prevent students from 
being overwhelmed upon arrival in-country and allow them time to acquire background information concerning each of the sites and institutions that will be visited. In addition to introducing the sites and institutions to be visited, guest speakers and presentations were used to introduce students to the differing cultures of the peers they will be interacting with during the course. These meetings also presented an opportunity for students to meet one another and become acquainted. The final purpose of the pre-trip meetings was to discuss the course logistics and preparing for everyone's arrival on the first day of the course.

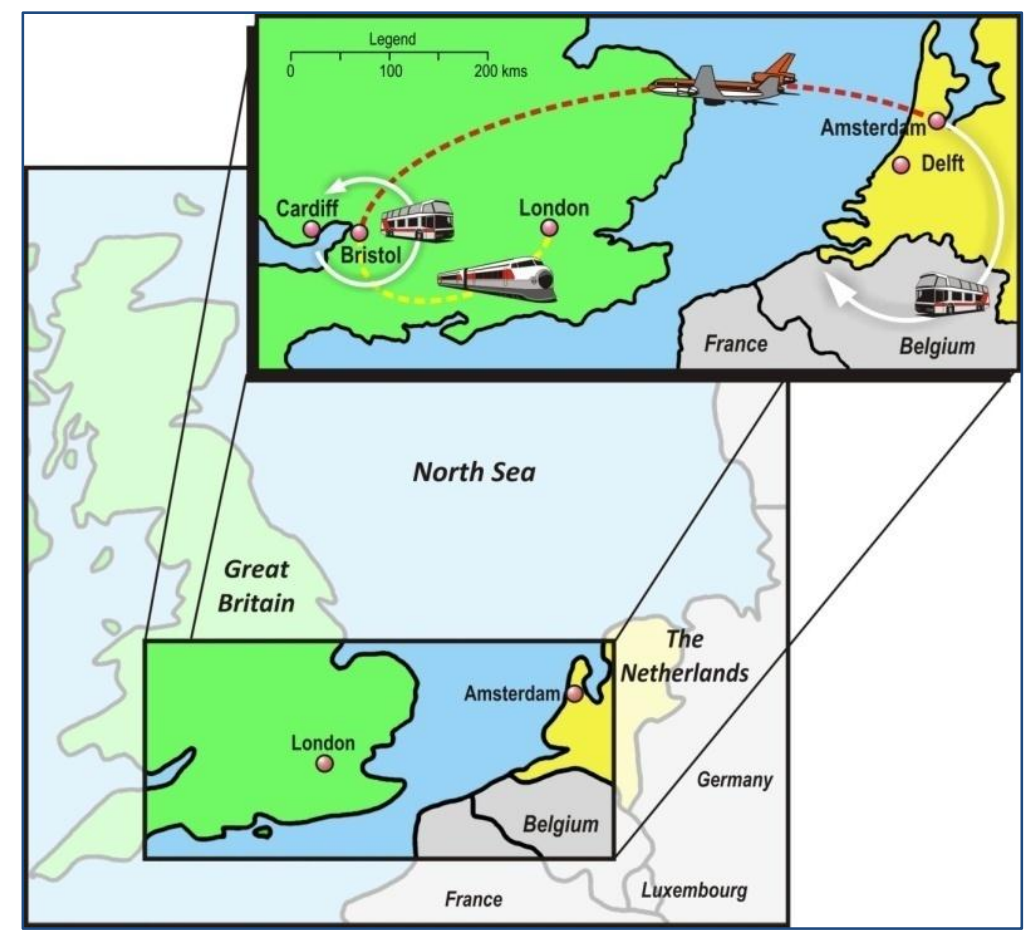

Figure 2: Itinerary of the IPWRSM Class in Europe 2010

Upon arrival of the course participants, the first official day started by meeting at UNESCO-IHE, where students had a chance to network with peers from the host institution. After ensuring everyone had settled in and had become acquainted with the town of Delft, the second day started by traveling by bus to Antwerp, Belgium where the group toured Flanders Hydraulics (Waterbouwkundig Laboratorim) and was presented various flood defense and research projects taking place in the Flanders region of Belgium. After visiting Flanders Hydraulics, the group traveled further south into Belgium to Temse. This was done to give the opportunity to travel by boat down the Sheldt River back into Antwerp. During the boat trip, the group stopped at the Sigma River Project where they learned how the water retention system is managed and how it is used to reduce inland tidal flood levels. While traveling down the Sheldt, students had the chance to discuss the engineering challenges that the river provided with students from the host institution. The third day was spent learning about and visiting the Delta Works flood defense project, with two major segments of this large-scale project being visited. 
A more research-oriented itinerary filled the fourth day, which started at UNESCO-IHE. Here Dr. Demetri Solomatine presented his research in hydroinformatics and Dr. Ann van Griensven presented her research in river basin management. Flood modeling, warning systems, and uncertainty and risk analysis were also discussed. Dr. Allen Bradley had a chance to present the Iowa Flood Center (IFC) to UNESCO-IHE and Dr. Marian Muste presented Hydrology for the Environment, Life and Policy (HELP). On the fifth day the group toured Deltares, a multinational research institute in Delft. Dr. Arthur E. Mynett, the president of Deltares, gave a presentation covering a variety of research topics the institute is currently investigating. The group was then given a tour of experimental and modeling laboratories. The group also got the chance to walk around the TU Delft campus. The weekend was spent experiencing the cultural and historical aspects of Amsterdam through a variety of guided tours.

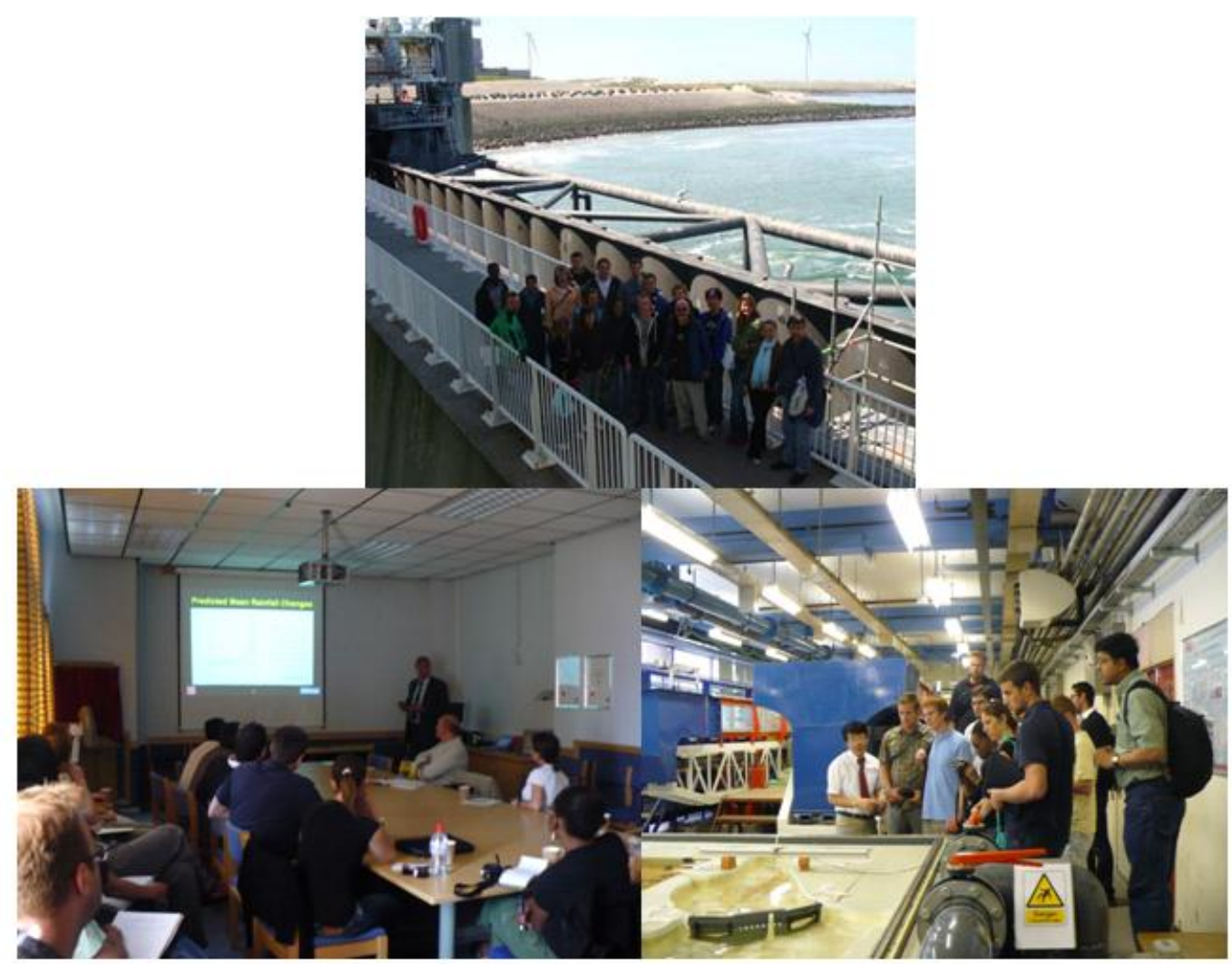

Figure 3: A range of engineered structures and research facilities were utilized to enhance students' educational experience

To begin the second half of the course the group traveled to Bristol, England to visit the University of Bristol campus. Students in the Geography Department and Civil Engineering Department gave presentations about the multitude of projects taking place at the institution, which include evapotranspiration estimation using numerical weather prediction (NWP), hydroinformatics, rainfall forecasting, hydrologic modeling, remote sensing, GIS and flood estimation, and non-structural flood mitigation. The ninth day saw the group taking a trip to 
Wales to visit Cardiff School of Engineering. The presented material highlighted research on the proposed Severn Barrage which will serve as a flood defense as well as tidal power. Professor Roger Falconer gave the group a tour around campus and downtown area, after which the group visited Environment Agency Wales. The next day group visited HR Wallingford, a well known independent water management research and consulting firm located between Oxford and London. The group was presented with current projects and toured the scale model facilities while learning about how the recently privatized firm meets the needs of the public. The group then visited Halcrow, a well-known private consulting firm that has a department working in flood risk management. Here some of the aspects of being a private professional engineer were presented to students to give an idea of how work culture differed from the United States.

On the eleventh day the group visited Environment Agency Midlands West Area and was shown flood defense research from the facility including their forecasting and warning system, flood risk management, and how they disseminate information of flood events to the public. Later in the day the group was taken to the Severn Ham in Tewkesbury where a recent historical flood took place. The last stop of the day was in Bewdley to see a demonstration of the demountable and temporary flood defense barriers, Demflood. The next day the group traveled to London and was hosted by Professor Čedo Maksimović at Imperial College London. Individuals from both schools presented their research and Dr. Allen Bradley introduced the IFC. Topics included modeling, management, and prediction of urban floods. An informal reception gave the group a chance to network with other students and professors. On the last day of the course the group visited the Thames Barrier.

In summary the course included 8 site visits, 3 lab visits, and 7 sightseeing visits. The group listened to 35 invited speakers and gave 11 IFC and IIHR presentations. Due to the structure of the course the group was also able to network with students and professors of the host institutions. In addition, the course introduced the culture and history of Delft, Den Haag, Antwerp, Amsterdam, Bristol, Cardiff, and London. Students learned about forecasting, integration of flood related issues such as risk analysis and management, hydroinformatics, the practical nature of academic research for supporting immediate societal needs, keen attention to the stakeholders' needs and their engagement in the decision making process, and innovative flood control structure for coastal and inland flood protection.

\section{Course Perception}

To determine the impact of the variety of experiences outlined, extensive post- and pre-trip surveys were completed by enrolled students of the 2010 offering of the course, as well as by students of the 2008-2009 course that travelled through Egypt. The surveys included open-ended and closed-ended questions that were aimed at gaining insight into the following subjects: student motivation for enrolling in the course, course expectations, fulfillment of course 
expectations, adequacy of pre-trip preparation, satisfaction with specific course elements and locations visited, level of student understanding of topics or challenges unique to the host country or region, cultural experiences, best and worst course experiences/elements, and recommendations for course improvement.

The closed-ended questions from both class' surveys were questions with a response that were based on a scale of 1-10 (with 10 representing the highest positive response). The pre-trip survey included questions to identify students' reasons for registering for IPWRSM with possible answers ranging from one (unimportant consideration) to ten (very important consideration). The student's t-test was used to evaluate the difference between group means for the significance in the difference between the pre-trip and post-trip survey responses. The null hypothesis posed for the test was that the means of the pre- and post-tests would be equal. Thus, percentages under $5 \%$ point to the alternative hypothesis being true on a $95 \%$ confidence interval or greater. This analysis also assumes that the two sets of samples are paired and the two populations are distributed normally. Thus statistically significant changes in student outlook can be ascertained. While evaluations of performance based changes in the students were not conducted, the course projects completed by students served to illustrate the knowledge gained through the course.

The stark differences between key questions provide evidence that the goals of the course are being met. Tables 2 and 3 on the following page illustrate some of this evidence. Table 2 provides the changes in students' familiarity with both the host countries society and their water resource engineering capacities. For both the United Kingdom and the Netherlands, students felt that they were much more acclimated to the local society. This also led them to feel more comfortable traveling alone internationally in general. Thus the class has been able to build students' confidence in being abroad. The perceived gains in knowledge of the water resources of each country reflect the impact of the thematic nature of the course. Similar results were reflected in the entrance and exit surveys of the course that travelled to Egypt. 
Table 2: Key changes in students perceptions illustrated by entrance and exit surveys

\begin{tabular}{l|ccc} 
Survey Question & Pre trip & Post-trip & t-test \\
\hline Comfort traveling alone to anywhere & $7.2 \pm 2.1$ & $8.3 \pm 1.4$ & $2.0 \%$ \\
\hline $\begin{array}{l}\text { How do you now rate your current level of } \\
\text { knowledge about society in the }\end{array}$ & $4.8 \pm 1.8$ & $7.2 \pm 1.6$ & $0.93 \%$ \\
$\begin{array}{l}\text { Netherlands? } \\
\text { How do you now rate your current level of } \\
\text { knowledge about society in the UK? }\end{array}$ & $5.7 \pm 2.1$ & $7.7 \pm 1.5$ & $2.3 \%$ \\
\hline $\begin{array}{l}\text { How would you now rate your current level } \\
\text { of knowledge about water resources } \\
\text { management issues in the Netherlands? }\end{array}$ & $5.5 \pm 2.4$ & $8.2 \pm 0.9$ & $0.13 \%$ \\
\hline $\begin{array}{l}\text { How would you now rate your current level } \\
\text { of knowledge about water resources } \\
\text { management issues in the UK? }\end{array}$ & $4.5 \pm 2.2$ & $7.7 \pm 1.0$ & $0.070 \%$ \\
\hline
\end{tabular}

Another significant section of questions that contributes to the concept that students are more acclimated to being in an international setting is shown in Table 3. When asked to rate the potential and actual significance of each potential issue during the class, students showed significant decreases in concern. The lowered fear of such things as making cultural faux pas and the inability to obtain money suggests the students will be more comfortable when traveling in the future.

Table 3: Responses to question inquiring into significance of potential problems

\begin{tabular}{l|ccc} 
Concern & Pre trip & Post-trip & t-test \\
\hline Language Barrier & $6.0 \pm 2.2$ & $2.2 \pm 1.7$ & $0.17 \%$ \\
\hline Personal Security & $5.4 \pm 2.7$ & $2.8 \pm 1.7$ & $1.6 \%$ \\
\hline Making a cultural faux pas & $6.8 \pm 2.3$ & $3.0 \pm 2.0$ & $0.030 \%$ \\
\hline Gender (specific roles and dress) & $5.2 \pm 2.1$ & $2.3 \pm 1.4$ & $0.30 \%$ \\
\hline $\begin{array}{l}\text { Money (ability to exchange cash, } \\
\begin{array}{l}\text { understand prices, tip } \\
\text { appropriately, etc.) }\end{array}\end{array}$ & $6.9 \pm 1.9$ & $4.1 \pm 2.7$ & $1.05 \%$ \\
\hline
\end{tabular}

These results support the claim that the overall objectives of the course -providing students a thematic course about water resources management as well as immersing them in another culture - were accomplished from the participants' perspective. Furthermore, based on the t-test evaluation, it is reasonable to assert that the difference in mean values was not random. The metric data is further supported by open-ended comments on the post-trip surveys. The results of the surveys for the 2010 program in the Netherlands and the United Kingdom were similar in many respects to those of the Egypt course in 2008. Eleven of the questions yielded statistically significant differences - five more categories than in 2008. Several of these significant differences overlapped with the observations from the Egypt course. The qualitative answers 
given by students on the 2010 surveys also reflect those of the 2008 surveys. When asked if students would pursue another IPWRSM opportunity in the future, all but one answered yes and several provided illuminating responses. Examples include:

- ...I had more personal gain than expected and more technical gain than I realized.

- ...(it is the) only chance to travel abroad affordably

Another component that students highlighted repeatedly was the value of interacting with international peers and colleagues. Some reactions:

- ...time with international peers and colleagues was enjoyable

- The two social outings, especially the one in London, were crucial for making contacts

The most important observation to take away from these surveys is that, in the opinion of the participants, these courses produce several important results. Students in both courses overwhelmingly reported significant gains in their understanding of water resources management issues in the countries visited. Moreover, they also indicated greater knowledge of society in those countries. This benefit, extending beyond the specific content of the course, is particularly relevant in this era of the global engineer. Besides increasing understanding of society in the host country, the courses also tangibly improved students' level of comfort traveling abroad. The fact that post-trip survey results from both courses showed students were significantly less concerned about language barriers, personal security and cultural faux pas afterwards supports the idea that courses such as this can improve a student's competency and confidence in international settings.

While the entrance surveys provided a useful baseline to evaluate changes in students' perceptions and the relative success in achieving the goals of the thematic short course, they also provided insight into what features of the course enticed students to enroll. This is valuable knowledge that can be used both to improve the course and to suggest how engineering study abroad courses in general can garner more success. A portion of the survey was devoted to polling students' on the importance of specific aspects when deciding to take the course. To determine which factors were rated significantly higher, a global mean response value was calculated as an expected value, mean response values for each criterion were compared to this global mean. Values that fell outside of one standard deviation were deemed to be significant.

The typical discussion of the obstacles facing engineering students when studying abroad can be complemented by the findings of what draws students to a program. It was found that factors not currently discussed heavily in the literature, such as networking and interest in meeting peers from other countries, were rated highly by students. Other criteria that rated highly were cultural 
exposure, the ability to tour non-tourist facilities, and cost. The IPWRSM model has attempted to incorporate an itinerary that consistently contains opportunities for networking and visits to facilities of note. These criteria may be placed more highly due to the fact that the thematic nature of the course is heavily advertised when trying to enroll students, and thus there is a certain expectation that engineering works and peers in other countries will be an important component of the class. The UK/Netherlands itinerary outlined above can be seen to aid in enrolling students, as it provided all of the criteria that students rated highly.

\section{Conclusion}

The under-representation of engineers within study abroad programs can be addressed by designing courses that cater to the specific needs of engineering students and their rigorous curriculum. The thematic short course based in an international setting presented here has been shown to both prepare students for the increasingly global nature of engineering projects while providing education on a specific topic. Due to the unique and highly condensed nature of the itinerary, students were exposed to a large breadth of engineering challenges and how they were addressed or are being studied. This condensed nature also provides advantages over typical study abroad experiences by removing some of the obstacles to enrollment. Engineering students do not have their rigorous curriculums interrupted and are presented with material that caters to their interests; both of which are concerns that prevent enrollment.

Each course offering provides technical and international activities that engage 15-20 U.S. scientists and engineers early in their careers in first-hand professional experience, preparing them for careers that are becoming increasingly global. The course academic credit and certificate may be used in degree requirements for water related disciplines with international dimensions. Paralleling host-country particularities with the American perspective in water resources management will add an international dimension to existing curricula that immediately and positively impact the quality of teaching, learning, and professional growth opportunities in various ways.

\section{Teaching}

- The IPWRSM course promotes understanding across technical programs and nations representing a solid investment in the future and prestige of IIHR and university departments, helping the University as a whole in the accreditation cycle and student retention. The established relationships also facilitate access to strong, highly qualified potential graduate students.

- The multidisciplinary international professional interactions facilitated by the course benefit instructors by sharing research results and brainstorming on implementation of different aspects of water resources aspects from a diverse and complementary perspective. These activities could lead to innovative solutions to water resources issues 
threatened by human and natural effects that can be implemented in policies and practices both in the U.S. and in the visited countries.

Learning

- The course uniquely strengthens participants' technical preparation by providing unique illustrations of the manner in which technical aspects of water resources management interface with socio-political, economical, sustainability, and international practices and policies. Most of the visits and workshops in the host countries included in the course are not accessible to the public, being specially tailored for the course needs.

- Bringing together U.S. and international participants from different disciplines sharing an interest in water and exposing them to practical demonstrations uniquely enhances their decision-making capabilities. Such an interdisciplinary and applied approach to water resources management instruction is difficult to achieve in the classroom.

Professional development

- The course offers the participants global perspective and opportunities for professional growth in the international arena. The personal contacts initiated during the visits can be subsequently converted in long-term direct and third-party international networks that facilitate collaborations, ideas and resource sharing, and life-long friendships.

- The academic credits given by an internationally known organization formally recognizes a level of proficiency in the global context that can considerably impact participants' career development. This innovative educational course contributes to preparing a wellqualified globally-engaged workforce capable of working for specialized companies overseas or worldwide missions in specialized international agencies such as USAID, World Bank, UN.

The offering of this creative and innovative course enhances engineering students, faculty and administration with study abroad experiences similar to their counterparts in literature and political and social sciences, providing a blueprint for international educational experiences for engineering disciplines. Use of water resources as the main course theme facilitates this endeavor because the nature of water resources management requires multi-disciplinary and often times international interactions. As we continue to refine the IPWRSM course, we are using the input of past course participants to lead us in developing a model course that appeals to the educational and professional development desires of engineering students while at the same time accommodating their often strict schedules. As further evaluations are performed we hope to create a model that can be successfully adopted by other universities. 


\section{References}

1. Altbach, Philip G., and Jane Knight. "The Internationalization of Higher Education: Motivations and Realities." Journal of Studies in International Education, 2007: 290-305.

2. Anderson, Philip A., Leigh Lawton, Richard J. Rexeisen, and Ann C. Hubbard. "Short-term study abroad and intercultural sensitivity: A pilot study." International Journal of Intercultural Relations, 2006: 457-469.

3. Armstrong, Gregory K. "Life After Study Abroad: A Survey of Undergraduate Academic Career Choices." The Modern Language Journal, 1984: 1-6.

4. ASCE. 1994. http://www.asce.org/Content.aspx?id=2147487305 (accessed January 26, 2010).

5. http://www.iihr.uiowa.edu/education/international/index.shtml.

6. Berkey, Dennis D. "International Education and Holistic Thinking for Engineers." Holistic Engineering Education, by D. Grasso and M.D. Burkins, 125-135. Springer Science+Business Media, 2010.

7. DiBiasio, David, and Natalie A. Mello. "Multilevel Assessment of Program Outcomes: Assessing a Nontraditional Study Abroad Program in the Engineering Disciplines." Frontiers: The Interdisciplinary Journal of Study Abroad, 2004: 237-252.

8. Gaddi, M., Sexton, T., Muste, M., Patel, V.C., and P. Alvarez, "International Perspectives in Water Resources Management: The Paraná River Watershed," World Transactions on Engineering \& Technology Education, 2:3, 435-439, 2003

9. Hirleman, Daniel E., Eckhard A. Groll, and Dianne L. Atkinson. "The Three Axes of Engineering Education." International Conference on Engineering Education - ICEE 2007. Coimbra, Portugal, 2007.

10. Institute of International Education. Fields of Study, Selected Years. 2010. http://opendoors.iienetwork.org/?p=35981 (accessed 2010).

11. Jurgens, Jill C., and Garrett McAuliffe. "Short-Term Study-Abroad Experience in Ireland: An Exercise in Cross-Cultural Counseling." International Journal for the Advancement of Counseling, 2004: 147-161.

12. King, Lynda J., and John A. Young. "Study Abroad: Education for the 21st Century." Die Unterrichtspraxis / Teaching German, 1994: 77-87.

13. Lohmann, Jack R., Howard A. Rollins, and J. Joseph Hoey. "Defining, developing, and assessing global competence in engineers." European Journal of Engineering Education, 2006: 119-131.

14. Marcum, John A. "What Direction for Higher Education? Eliminate the Road Blocks." Chronicle of Higher Education, 2001.

15. McHargue, Carl, and Eleanor Baum. "Enhancement of the Global Perspective for Engineering Students by Providing an International Experience: An Academic View - Europe." 2003 ECI Conference on Enhancement of the Global Perspective for Engineering Students by Providing an International Experience. Tomar, Portugal, 2005. 5.

16. McHugo, Gregory J., and G. Christian Jernstedt. "The Affective Impact of Field Experience Education on College Students." Alternative Higher Education, 1979: 188-206.

17. Mutel, C.F., Flowing Through Time: A History of the Iowa Institute of Hydraulic Research Published by the Iowa Institute of Hydraulic Research, Iowa City, Iowa, 1998.

18. Nasr, Karim, Joel Berry, Giancarlo Taylor, William Webster, Raghu Echempati, and Ram Chandran. "Global Engineering Education Through Study-Abroad Experiences: Assessment and Lessons Learned." 2002 ASEE/ SEFI/TUB Colloquium. Flint, MI: American Society for Engineering Education, 2002.

19. NSF (2001). "Looking Beyond the Borders: A Project Director's Handbook of Best Practices for International Research Experiences for Undergraduates," NSF Workshop, University of Buffalo, Buffalo, NY (http://www.nsftokyo.org/REU/).

20. NSF (2004). "Partnerships for International Research and Education," Program Solicitation 05-533 National Science Foundation, Arlington, VA.

21. NSTC (2000). "Ensuring a Strong U.S. Scientific, Technical, and Engineering Workforce in the 21st Century," National Science and Technology Council Report, the White House, Washington, D.C. 
22. Parkinson, Alan. "Engineering Study Abroad Programs: Formats, Challenges, Best Practices." Online Journal for Global Engineering Education, 2007.

23. Praetzel, Gary D., James Curcio, and Joseph Dilorenzo. "Making Study Abroad a Reality for All Students."

24. Schaefer, Michael, Jessica Smith, Carmen Langel, Dustin Tardiff, and Marian Muste. "International Perspectives in Water Science \& Management: Evaluation of a Short-Term International Engineering Course." Iowa City, Iowa, 2009. 